\title{
Neonatal tumours: A single centre review
}

\begin{tabular}{|c|c|}
\hline $\begin{array}{l}\text { Authors: } \\
\text { Tanya M. Schi } \\
\text { Diane Mackin }\end{array}$ & $\begin{array}{l}\text { kerling }{ }^{1} \\
\operatorname{ton}^{2}\end{array}$ \\
\hline $\begin{array}{l}\text { Affiliations: } \\
{ }^{1} \text { Division of Pa } \\
\text { Haematology } \\
\text { Department o } \\
\text { and Child Hea } \\
\text { Maxeke Johan } \\
\text { Academic Hos } \\
\text { Health Scienc } \\
\text { the Witwaters } \\
\text { South Africa }\end{array}$ & $\begin{array}{l}\text { ediatric } \\
\text { and Oncology, } \\
\text { f Paediatrics } \\
\text { th, Charlotte } \\
\text { nesburg } \\
\text { pital, Faculty of } \\
\text { s, University of } \\
\text { rand, }\end{array}$ \\
\hline $\begin{array}{l}{ }^{2} \text { Division of Pa } \\
\text { Haematology } \\
\text { Department } \\
\text { and Child Hea } \\
\text { Baragwanath } \\
\text { Hospital, Facu } \\
\text { Sciences, Univ } \\
\text { Witwatersran }\end{array}$ & $\begin{array}{l}\text { ediatric } \\
\text { and Oncology, } \\
\text { f Paediatrics } \\
\text { th, Chris Hani } \\
\text { Academic } \\
\text { ty of Health } \\
\text { ersity of the } \\
\text { l, South Africa }\end{array}$ \\
\hline $\begin{array}{l}\text { Correspondin } \\
\text { Tanya Schicke } \\
\text { tmschickerling }\end{array}$ & $\begin{array}{l}\text { author: } \\
\text { ling, } \\
\text { @gmail.com }\end{array}$ \\
\hline $\begin{array}{l}\text { Dates: } \\
\text { Received: } 22 \mathrm{~J} \\
\text { Accepted: } 26 \\
\text { Published: } 28\end{array}$ & $\begin{array}{l}\text { une } 2017 \\
\text { uly } 2017 \\
\text { Sept. } 2017\end{array}$ \\
\hline $\begin{array}{l}\text { How to cite th } \\
\text { Schickerling T } \\
\text { D. Neonatal tc } \\
\text { centre review. } \\
\text { 2017;1(0), a2 } \\
\text { org } / 10.4102 / s\end{array}$ & $\begin{array}{l}\text { is article: } \\
\text { h, Mackinnon } \\
\text { mours: A single } \\
\text { S. Afr. j. oncol. } \\
\text { https://doi. } \\
\text { ajo.v1i0.24 }\end{array}$ \\
\hline $\begin{array}{l}\text { Copyright: } \\
\text { C 2017. The } A \\
\text { Licensee: AOS } \\
\text { is licensed un } \\
\text { Creative Com! } \\
\text { Attribution Lic }\end{array}$ & $\begin{array}{l}\text { uthors. } \\
\text { S. This work } \\
\text { ler the } \\
\text { nons } \\
\text { ense. }\end{array}$ \\
\hline Read online: & \\
\hline 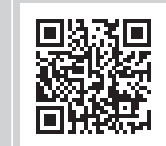 & $\begin{array}{l}\text { Scan this QR } \\
\text { code with your } \\
\text { smart phone or } \\
\text { mobile device } \\
\text { to read online. }\end{array}$ \\
\hline
\end{tabular}

Background: Neonatal tumours, occurring within 28 days of life, are associated with a favourable outcome in high-income countries. Limited data are available on neonatal tumours in low- and middle-income countries.

Aim: We aimed to create awareness of neonatal tumours in a middle-income country, by identifying the most common tumours diagnosed to determine whether there was a delay to presentation or diagnosis at the Paediatric Oncology unit, to identify possible areas of improvement and increase overall survival.

Setting: Chris Hani Baragwanath Academic Hospital Paediatric Oncology unit.

Methods: A retrospective case series was performed collecting data on 60 neonates diagnosed with a tumour over a 25-year period (1 January 1988 to 31 December 2012). Descriptive statistical analysis using percentages and medians were used. Kaplan-Meier analysis was used to calculate survival.

Results: Germ cell tumours were identified as the most common neonatal tumours diagnosed $29 / 60(48.3 \%)$, whereas malignant soft tissue tumours were the most common malignant tumours identified. The median delay to presentation was 7 days, the median diagnostic delay was 11 days and the median overall delay was 30 days. The overall 5-year survival rate was $67.3 \%$, with an overall 5-year survival of $54.1 \%$ of neonates diagnosed with a malignant tumour.

Conclusion: A large percentage of neonates diagnosed with malignant tumours in highincome countries can be successfully treated and cured. Clinicians involved in the care of neonates need to be better acquainted with disease-specific signs of neonatal tumours to allow for early detection and referral to a Paediatric Oncology unit.

\section{Introduction}

A tumour is defined as a mass of new tissue that persists and grows independently of its surrounding structures and can be classified as benign or malignant. ${ }^{1}$

Neonatal tumours occur within the first 28 days of life. ${ }^{2,3,4,5,6,7}$ These tumours are known to be very rare, with an incidence of $1 / 12500$ to $1 / 17300$ total births..$^{8,9,10,11}$ The accuracy of this reported incidence is debatable, for most case series reviewed did not leave room for late presentations. ${ }^{3,4,5,6,8,12,13}$

It has been predicted that most neonatal units will see at least one patient with a neonatal tumour every 1 to 2 years. ${ }^{9}$ This incidence was reported in neonatal units with approximately 7500 deliveries a year. ${ }^{9}$ The obstetric unit at Chris Hani Baragwanath Academic Hospital sees about 17000 deliveries annually. This large number of patients leaves a lot of room for missed diagnoses and late referrals.

Neonatal tumours often present and behave differently to those in older children. ${ }^{2,3,4,5,7,9,14,15}$ In childhood cancer, an early diagnosis allows for early treatment, which has a much greater chance of success and diagnostic delay is one of the predominant causes of disseminated malignancies. ${ }^{16,17}$ Because of the rarity of neonatal malignancies, this has not been explored; however, it probably plays a significant role in overall survival.

The aim of this study was to describe the distribution of neonatal tumours diagnosed in patients referred to Chris Hani Baragwanath Academic Hospital Paediatric Oncology unit. We aimed to identify the most common tumours diagnosed, the age at presentation, the presenting signs, treatment received, and the outcomes. We attempted to identify factors that might improve overall survival. 


\section{Research, methods and design}

The clinical records of patients diagnosed with benign and malignant tumours, at Chris Hani Baragwanath Academic Hospital Paediatric Oncology unit, from 1 January 1988 through to 31 December 2012 were reviewed. The presenting signs, pathologies, treatments and outcomes of all patients who presented before 3 months of age were recorded.

Chris Hani Baragwanath Academic Hospital is regarded as the third largest hospital in the world, occupying around 0.70 km², with approximately 3200 beds..$^{18}$ Nearly 60000 patients are treated in the Maternity Hospital every year and approximately 17000 babies are born annually. ${ }^{18}$ Because of this large number of patients, there is often a delay in the referral of patients to the appropriate disciplines. We therefore included patients who presented to the Paediatric Oncology unit before the age of 3 months, to leave room for the anticipated delay.

Patients who displayed disease-specific signs before 28 days of life were included in the study. Patients diagnosed with haematological malignancies were excluded and because of the inconsistency in the referral of patients with haemangiomas, either to Paediatric Surgery or Paediatric Oncology, these patients were also excluded. Patients with incomplete records were not included in this study.

Data were analysed using percentages and medians and the overall survival was calculated with Kaplan-Meier analysis.

\section{Ethical considerations}

Ethics approval was obtained from the Human Research Ethics Committee (Medical) of the University of the Witwatersrand (Clearance certificate no. M130257).

\section{Results}

Sixty neonates, less than 3 months of age, diagnosed with a tumour in the 25-year period, who displayed disease-specific signs before 28 days of life, were identified.

Germ cell tumours were the most common tumours diagnosed $(29 / 60,48.3 \%)$, followed by soft tissue tumours $(12 / 60,20 \%)$, hepatic tumours $(6 / 60,10 \%)$, renal tumours $(5 / 60,8.3 \%)$, neuroblastomas $(3 / 60,5 \%)$, retinoblastomas $(3 / 60,5 \%)$ and central nervous system tumours $(2 / 60,3.3 \%)$, of which 44 were benign tumours (Table 1 and Figure 1).

Sixteen patients were diagnosed with malignant tumours, of which malignant soft tissue tumours $(7 / 16,43.7 \%)$ were the most common, followed by neuroblastomas (3/16, 18.8\%), retinoblastomas $(3 / 16,18.8 \%)$, malignant germ cell tumours $(1 / 16,6.3 \%)$, hepatoblastomas $(1 / 16,6.3 \%)$ and central nervous system tumours $(1 / 16,6.3 \%)$ (Table 1 and Figure 2$)$. The majority of patients $(54 / 60,90 \%)$ displayed diseasespecific signs at birth. The median delay to presentation

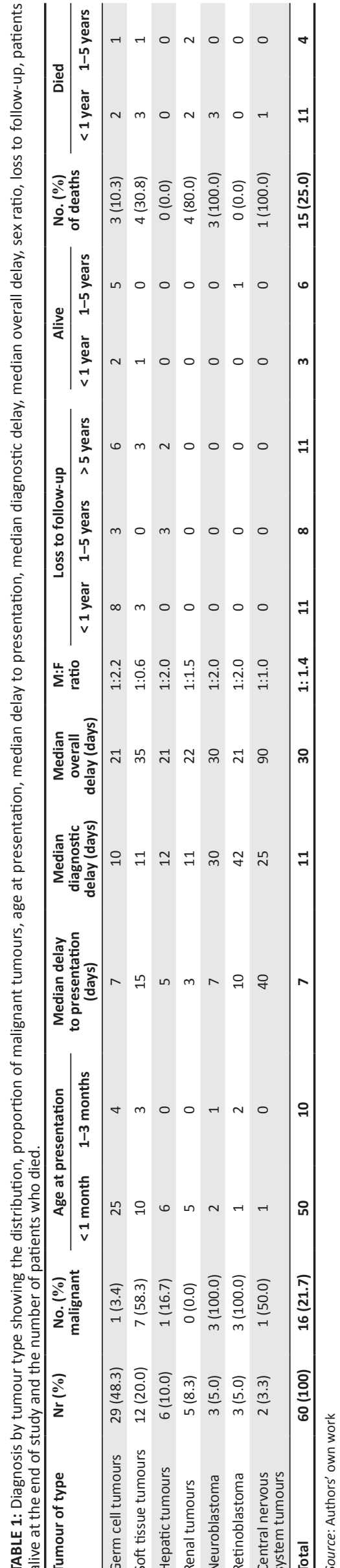




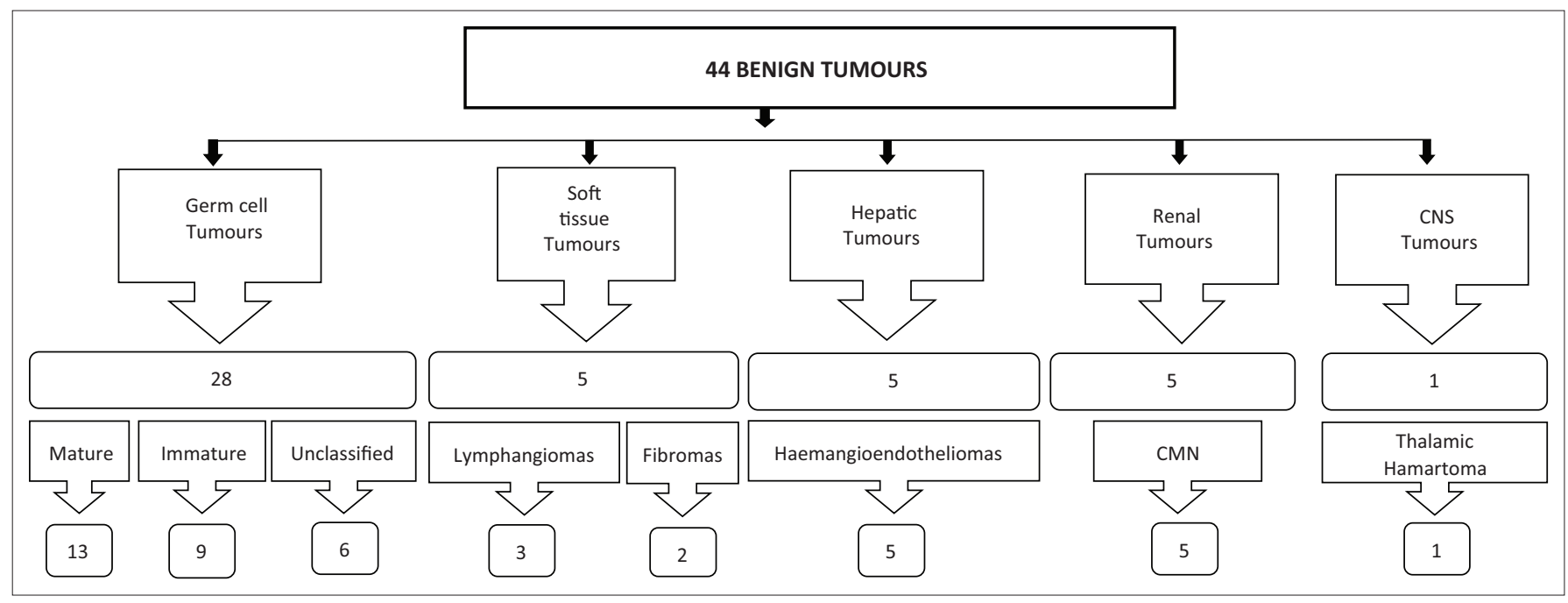

Source: Authors' own work

CNS, central nervous system; CMN, congenital mesoblastic nephroma.

FIGURE 1: The distribution of patients diagnosed with benign neonatal tumours.

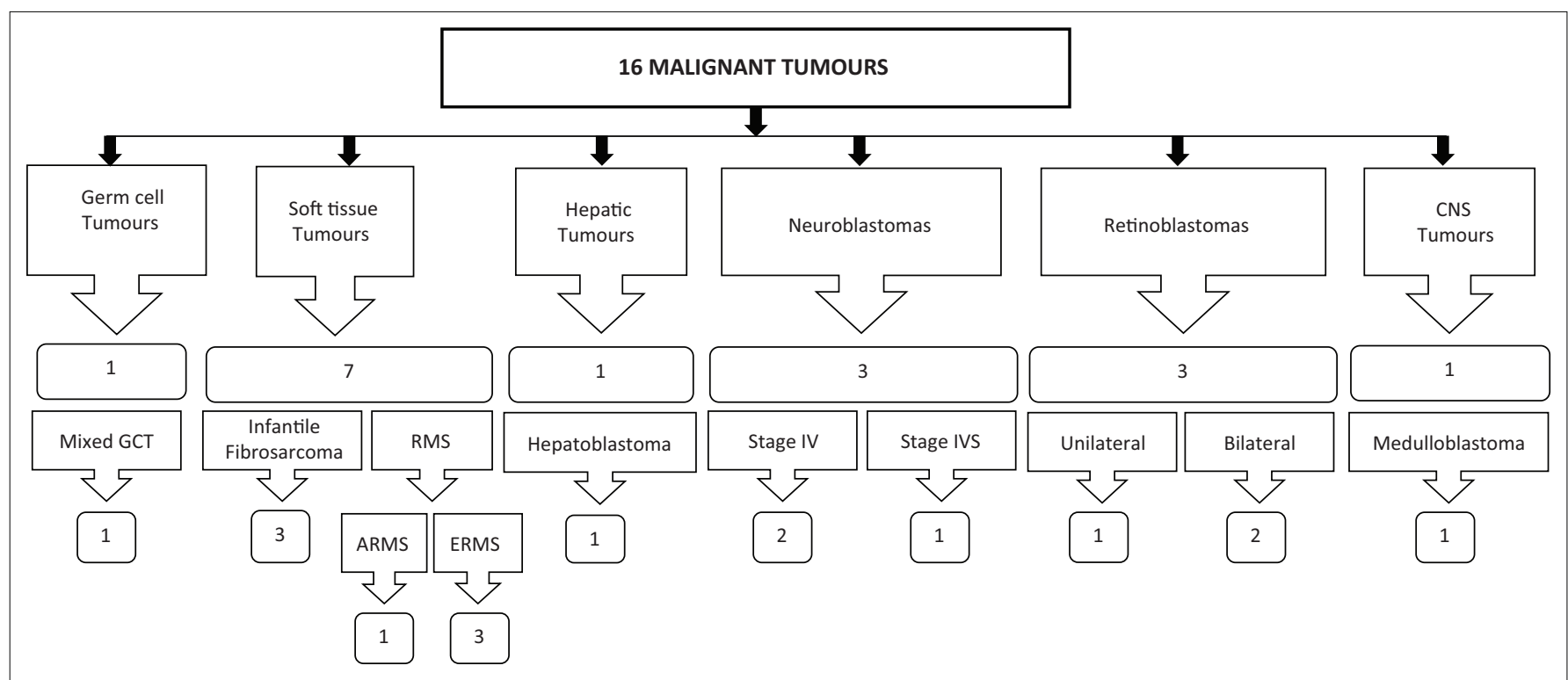

Source: Authors' own work

CNS, central nervous system; GCT, germ cell tumours; RMS, rhabdomyosarcoma; ARMS, alveolar rhabdomyosarcoma; ERMS, embryonal rhabdomyosarcoma.

FIGURE 2: The distribution of patients diagnosed with malignant neonatal tumours.

to the Paediatric Oncology unit was 7 days, the median diagnostic delay was 11 days and the median overall delay was 30 days.

Forty-nine patients were born in Gauteng, 16/49 (32.7\%) at Chris Hani Baragwanath Academic Hospital and 33/49 $(66.3 \%)$ elsewhere in the province. Patients born at Chris Hani Baragwanath Academic Hospital exhibited a median delay to presentation to the Paediatric Oncology unit of 3 days, a median diagnostic delay of 9 days and a median overall delay of 30 days. Of those patients born elsewhere in Gauteng, the median delay to presentation to the Paediatric Oncology unit was 8 days, the median diagnostic delay was 11 days and the median overall delay was 22 days. Eleven patients were referred from outside the province with a median delay to presentation to the Paediatric Oncology unit of 11 days, a median diagnostic delay of 8 days and a median overall delay of 30 days.

Of the 16 patients born at Chris Hani Baragwanath Academic Hospital, 6 patients were diagnosed with germ cell tumours, 5 with soft tissue tumours, 3 with hepatic tumours, 1 with a renal tumour and 1 with a neuroblastoma. Of these, five patients were diagnosed with malignant tumours. Of the 33 patients born elsewhere in Gauteng, 17 were diagnosed with germ cell tumours, 6 with soft tissue tumours, 3 with renal tumours, 3 with retinoblastomas, 2 with hepatic tumours, and 2 with central nervous system tumours. Of these, 8 patients were diagnosed with malignant tumours. Of the 11 patients born outside the province, 6 were diagnosed with germ cell tumours, 2 with neuroblastomas, 1 with a soft tissue tumour, 1 with a hepatic tumour and 1 with a renal tumour. Of these, 3 patients were diagnosed with malignant tumours. 
There were 25 male and 35 female patients with an M:F ratio of 1:1.4 (Table 1).

In this study, 34/60 (56.7\%) patients underwent surgery; 9/60 (15\%) patients received chemotherapy; 9/60 (15\%) patients underwent surgery and received chemotherapy; $4 / 60(6.7 \%)$ patients underwent surgery, received chemotherapy and radiation therapy; $1 / 60$ (1.7\%) patient received chemotherapy and radiation therapy. Of those patients who only underwent surgery, four died. Of the nine patients who only received chemotherapy, four died, of which three were from treatment-related complications. Of the nine patients who underwent surgery and received chemotherapy, two died, of which one was from treatmentrelated complications. Of the four patients who underwent surgery and received chemotherapy and radiation therapy, two died. The one patient who received chemotherapy and radiation therapy died from disease progression. The overall treatment-related mortality was $4 / 60(6.7 \%)$, all from treatment-related neutropaenic sepsis and the overall treatment-related mortality in malignant tumours was 3/16 (18.8\%).

Thirty patients were lost to follow-up, of which $24 / 30$ (80\%) were diagnosed with benign tumours and 6/30 (20\%) with malignant tumours. All patients diagnosed with malignant tumours completed treatment before they were lost to follow-up.

The overall survival of patients diagnosed with a neonatal tumour at 1, 2 and 5 years was $78.5 \%, 76.2 \%$ and $67.3 \%$, respectively (Figure 3 ). The overall survival of patients diagnosed with malignant tumours at 1 and 2 years was $61.9 \%$ and $54.1 \%$, respectively (Figure 4 ). There were no deaths recorded in patients diagnosed with a malignant tumour after 395 days of life.

\section{Germ cell tumours}

Twenty-nine patients were diagnosed with germ cell tumours, of which 28 patients were diagnosed with

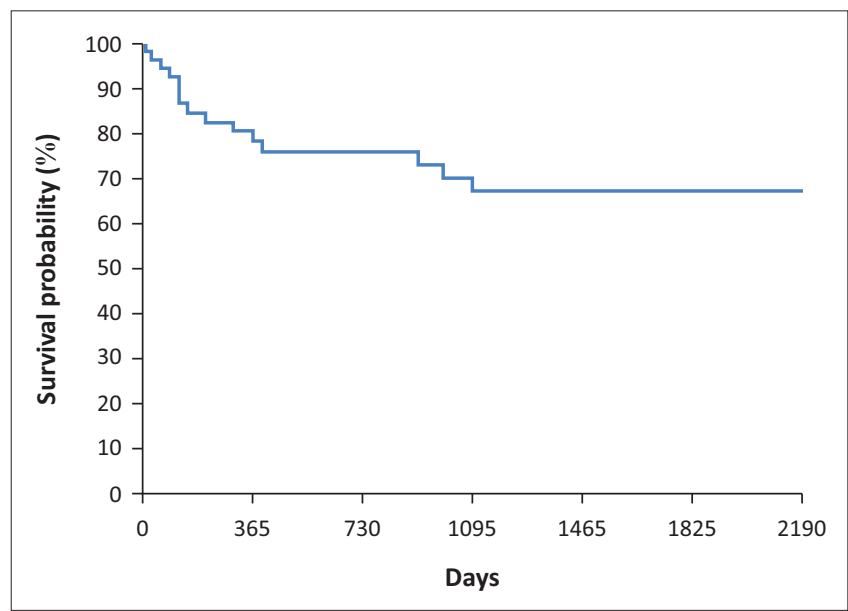

Source: Authors' own work

FIGURE 3: Kaplan Meier graph. Overall survival of the studied patients diagnosed with benign and malignant neonatal tumours. teratomas and 1 with a mixed germ cell tumour. Of the patients diagnosed with teratomas, 13 were mature, 9 immature and 6 unclassified teratomas (Figure 1). The most common site was the sacrococcygeal region $24 / 29$ $(82.8 \%)$. Other sites included the head and neck $(3 / 29$, $10.3 \%)$ and the intra-abdominal region $(2 / 29,6.9 \%)$. Twenty-six patients $(89.7 \%)$ displayed disease-specific signs at birth, which included a mass in 25/26 (96.2\%) patients and seizures, as a result of an intracranial mass, in $1 / 26(3.8 \%)$ patient.

Twenty-one of the 28 (75\%) patients diagnosed with benign teratomas were treated with surgery alone and disease recurrence was seen in $6 / 28(21.4 \%)$ patients. Three patients were diagnosed with immature teratomas, two with mature teratomas and one with an unclassified teratoma. Five patients with recurrent disease were treated with chemotherapy and one patient underwent a second surgical resection.

Three patients diagnosed with benign teratomas died. One patient diagnosed with a cervical teratoma underwent surgical resection but presented with recurrent disease two and a half years later. Repeated surgical resection was unsuccessful and the patient died from progressive disease before further treatment could be initiated. The second patient was diagnosed with a sacrococcygeal teratoma. He underwent surgical resection but presented with disease recurrence secondary to incomplete resection. Despite chemotherapy, the patient died from disease progression. The third patient was diagnosed with an intracranial teratoma and died before treatment could be initiated.

The patient diagnosed with a mixed germ cell tumour presented at birth with a sacrococcygeal mass. The mass was resected and histology confirmed a mature teratoma with yolk sac elements. She received chemotherapy and was alive and disease free at the end of the study.

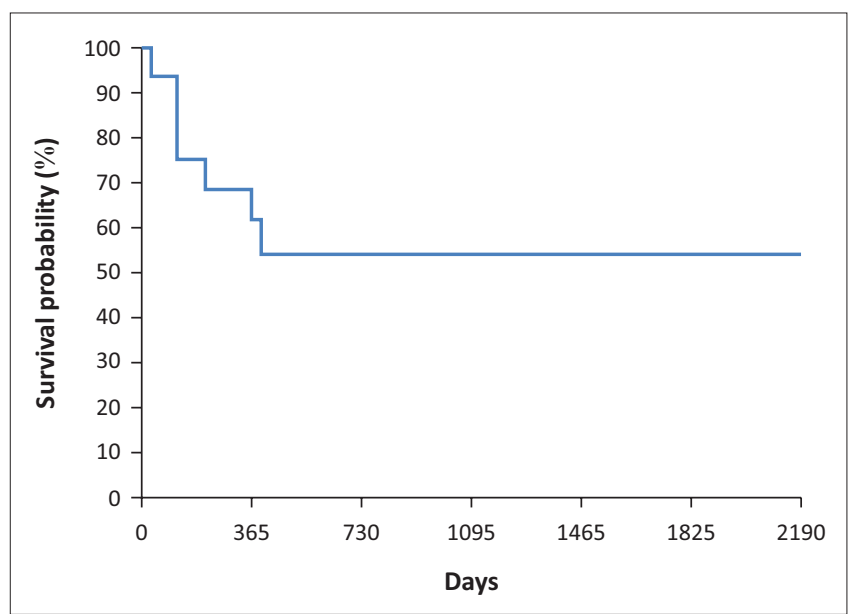

Source: Authors' own work

FIGURE 4: Kaplan Meier graph. Overall survival of the studied patients diagnosed with malignant neonatal tumours. 


\section{Soft tissue tumours}

Twelve patients were diagnosed with soft tissue tumours, $5 / 12(41.7 \%)$ with benign and $7 / 12(58.3 \%)$ with malignant tumours. Of the patients diagnosed with benign tumours, three were diagnosed with lymphangiomas and two with fibromas. Of the patients diagnosed with lymphangiomas, all three presented with a thoracic mass present from birth. Of the two patients diagnosed with fibromas, both presented with masses on the lower extremities present from birth.

Of the patients diagnosed with malignant tumours, $4 / 7$ (57.1\%) were diagnosed with rhabdomyosarcomas and $3 / 7$ $(42.9 \%)$ with infantile fibrosarcomas. Of the patients diagnosed with rhabdomyosarcomas, three were diagnosed with embryonal rhabdomyosarcomas and one with an alveolar rhabdomyosarcoma (Figures 1 and 2). Of the patients diagnosed with embryonal rhabdomyosarcomas, two presented with a mass on the soles of their feet and one with a mass in the paranasal region. The patient diagnosed with an alveolar rhabdomyosarcoma presented with a mass below the eye. All four patients displayed disease-specific signs present from birth.

Of the patients diagnosed with infantile fibrosarcomas, two exhibited a mass on the upper extremities and one a mass on the thorax. All patients displayed disease-specific signs present from birth.

One patient diagnosed with an embryonal rhabdomyosarcomas on the sole of the foot received chemotherapy only and remission was achieved post treatment. The patient diagnosed with an embryonal rhabdomyosarcoma of the paranasal region received chemotherapy but died from neutropaenic sepsis during treatment. The remaining two patients received chemotherapy, but because of a poor clinical response, they required surgical resection and radiation therapy. Of these, one patient was diagnosed with an embryonal rhabdomyosarcoma on the sole of the foot. He completed treatment, achieved remission but was lost to follow-up post treatment. The second patient was diagnosed with an alveolar rhabdomyosarcoma and died from disease progression at 1 year of age.

Two of the three patients diagnosed with infantile fibrosarcomas received chemotherapy only and remission was achieved post treatment. One patient with an infantile fibrosarcoma of the chest wall, underwent surgical resection and received chemotherapy, but because of the size, extension and anatomical location of the mass, complete resection was not possible. The patient received radiation therapy but died from disease progression.

\section{Hepatic tumours}

Six patients were diagnosed with hepatic tumours, 5/6 $(83.3 \%)$ with haemangioendotheliomas and 1/6 (16.7\%) with a hepatoblastoma (Figures 1 and 2). Of the five patients with haemangioendotheliomas, two presented with an abdominal mass, two with jaundice and one with abdominal distension. All five patients displayed disease-specific signs present from birth. The patient diagnosed with a hepatoblastoma presented with an abdominal mass present from birth.

Three of the five patients with haemangioendotheliomas received only medical treatment, one underwent surgery and one patient received both surgery and medical treatment. The patient with a hepatoblastoma received chemotherapy and surgery, completed treatment, achieved remission but was lost to follow-up after 4 years.

\section{Renal tumours}

Five patients were diagnosed with congenital mesoblastic nephromas and presented with an abdominal mass present from birth (Figure 1). All five patients underwent primary nephrectomies. The tumour mass was incompletely resected in one patient, who presented with disease recurrence 3 months later. The patient received chemotherapy but died at 10 months of age from neutropaenic sepsis. Three patients died from unrelated causes, two from complications of human immunodeficiency virus and one patient from complications of prematurity. One patient was discharged from Paediatric Oncology at 9 years of age and referred to Paediatric Nephrology for follow-up.

\section{Neuroblastoma}

Three patients were diagnosed with neuroblastomas, two with stage IV and one with stage IVS disease (Figure 2). All three patients presented with abdominal distension. Both patients with stage IV disease received chemotherapy and the patient with stage IVS disease developed abdominal compartment syndrome from disease progression and required surgical intervention and chemotherapy. Two patients died from neutropaenic sepsis and the patient with stage IVS disease died from necrotising enterocolitis secondary to abdominal compartment syndrome.

\section{Retinoblastomas}

Three patients were diagnosed with retinoblastomas, two with bilateral and one with unilateral disease (Figure 2). One of the patients diagnosed with bilateral disease was asymptomatic but screened because of a positive family history. One patient presented with leucocoria and one with proptosis.

One patient with bilateral disease had eye salvage with chemotherapy alone. The second patient with bilateral disease underwent enucleation of one eye and received chemotherapy and radiation therapy. The patient with unilateral disease underwent enucleation without requiring further treatment. All three patients were alive at the end of the study.

\section{Central nervous system tumours}

Two patients were diagnosed with central nervous system tumours, one with a medulloblastoma and one with a 
thalamic hamartoma (Figures 1 and 2). The patient diagnosed with a medulloblastoma presented with macrocephaly and congenital hydrocephalus. The patient with a thalamic hamartoma was one of twins, born prematurely at 34 weeks and a thalamic mass was detected on routine cranial sonar.

The patient diagnosed with a medulloblastoma, received chemotherapy but died from disease progression and the patient with a thalamic hamartoma died before any treatment could be initiated.

\section{Discussion}

This review reports on a single centre's experience, in a middle-income country, in neonatal tumours over a 25-year period. Two to three patients diagnosed with a neonatal tumour were identified per year. According to a study conducted at John Radcliffe Children's Hospital in Oxford, most neonatal units will see one case every $1-2$ years. ${ }^{9}$ This is data based on neonatal units in high-income countries, with an average of 7500 deliveries annually. ${ }^{9}$ Even though the number of deliveries at Chris Hani Baragwanath Academic Hospital has increased over the past 25 years, patients from all over the country are referred here for tertiary care. Because of this large patient population, we concluded that the incidence of neonatal tumours in this study was probably underestimated. The lack of appropriate referrals, where disease-specific signs were either missed or incorrectly interpreted, poor social circumstances and the difficulty in reaching a healthcare centre and the fact that neonatal deaths and stillborn babies did not undergo post-mortem examinations suggested that some tumours might have remained undiagnosed.

In this study, the high proportion of the germ cell tumours in neonates, reaching almost $50 \%$, is in keeping with reported data. Red Cross War Memorial Children's Hospital reviewed the clinical records of neonates diagnosed with solid tumours over a 34-year period and identified 31/66 (47\%) patients with germ cell tumours. ${ }^{12}$ A study conducted in Glasgow included benign and malignant solid tumours and the majority of patients $(19 / 51,37.3 \%)$ were diagnosed with germ cell tumours. ${ }^{3}$ A study conducted in Durham included haemangiomas and $8 / 23(34.8 \%)$ patients were diagnosed with germ cell tumours. ${ }^{4}$

Several studies only reviewed patients diagnosed with malignant neonatal tumours. $5,7,8,19$ The largest of these studies were conducted in France, where they identified 285 neonates from the French National Registry of Childhood Solid Tumours with malignant tumours over a 9-year period. ${ }^{19}$ Neuroblastomas were identified as the most common malignant solid tumour diagnosed and comprised $134 / 285(47 \%)$ of the patient population. ${ }^{19}$ This was followed by malignant germ cell tumours $(82 / 285$, $28.8 \%)$, central nervous system tumours (30/285, 10.5\%), soft tissue sarcomas $(24 / 285,8.4 \%)$, retinoblastomas $(8 / 285$, $2.8 \%)$, renal tumours $(5 / 285,1.8 \%)$ and hepatoblastomas $(3 / 285,1.1 \%){ }^{19}$
Other studies conducted in high-income countries also identified neuroblastomas as the most frequently diagnosed malignant neonatal tumours followed by retinoblastomas, malignant germ cell tumours, renal tumours and hepatoblastomas. $5,7,8$

In this study, malignant soft tissue tumours were identified as the most common malignant tumour diagnosed in neonates and included 7/16 (43.8\%) patients.

A much lower rate of retinoblastomas was reported in this study compared with studies conducted in high-income countries. This can most likely be attributed to the incorrect interpretation or the lack of detecting disease-specific signs like leucocoria. We also demonstrated a much lower incidence of central nervous system tumours, which can possibly be explained by the lack of early detection.

The distribution of childhood cancer in South Africa, occurring in children from birth to 4 years, has recently been reviewed by the South African Children's Study Cancer Group using the South African Children's Tumour Registry. ${ }^{20}$ Although this study included all children diagnosed with malignancies before the age of 14 years, the patient population was divided into groups, with one only including patients from birth to 4 years. ${ }^{20}$ This study reviewed patients diagnosed with haematological malignancies and malignant solid tumours; however, the most frequently diagnosed malignant solid tumours in this age group were renal tumours. This was followed by retinoblastomas, neuroblastomas, central nervous system tumours and soft tissue sarcomas. ${ }^{20}$ Even though these findings cannot directly be compared to the distribution of malignant tumours in our study; this study described a lower distribution of patients diagnosed with neuroblastoma, which was not in keeping with the distribution reported in high-income countries. These findings suggested that the distribution of malignant tumours may vary in different ethnic groups and geographical locations and this might account for the low number of patients diagnosed with neuroblastomas in our study. ${ }^{6}$

The male predominance of malignant tumours in the neonatal period in this study is in keeping with similar studies conducted in high-income countries..$^{8,13}$

Tumours in the neonatal period usually present with a mass, and $46 / 60(76.7 \%)$ patients in this study presented with a mass, of which $45 / 46(97.8 \%)$ were present from birth. ${ }^{2,5}$

Even though the majority of patients in this study displayed disease-specific signs present from birth, we reported a median overall delay of 30 days. Diagnostic delay was identified as the major contributing factor, and the median delay to presentation to the Paediatric Oncology unit was only 7 days. Patients born within Gauteng had the lowest median delay to presentation to the Paediatric Oncology unit but revealed the highest median diagnostic delay. This delay cannot be justified, and the types of tumours diagnosed were 
similar in all three referral groups. The median diagnostic delay was 12 days and this can possibly be explained by the shortage of medical staff and staff at laboratory services at public hospitals. Advances in histopathology over the last couple of years now allow for more rapid and more accurate assessment of tumour masses.

In this study, patients diagnosed with retinoblastomas exhibited the highest diagnostic delay of 42 days. This delay cannot be justified, for the diagnosis of retinoblastomas is made on clinical findings; therefore, no diagnostic delay should exist.

Half of the patients in this study were lost to follow-up, of which the majority of patients were diagnosed with benign tumours. All the patients diagnosed with malignant tumours who were lost to follow-up completed treatment. This extremely high loss to follow-up rate can perhaps be explained by the poor socioeconomic status of most patients seen in the public sector, who do not have the financial means to attend the clinic on a regular basis. Most of the patients who were lost to follow-up were referred from other centres in Gauteng and Chris Hani Baragwanath Academic Hospital was not regarded as the easiest accessible medical centre for these patients.

In this study, we reported an overall survival of $67.3 \%$, which is in keeping with studies that analysed data of neonates diagnosed with malignant and benign tumours. A study performed in Glasgow analysed data of 51 neonates and reported an overall survival of $67 \% .^{3}$

Fifteen patients in this study died and the overall treatmentrelated mortality was $4 / 60(6.7 \%)$, which is in keeping with the study conducted in Glasgow that reported overall treatment-related mortality of $5.9 \% .^{3}$

The majority of studies only reported on malignant neonatal tumours. In this study, the overall survival of the patients diagnosed with malignant tumours was $54.1 \%$. This is significantly lower compared with studies conducted in high-income countries. A study performed in Poland analysed the data of 37 neonates and reported an overall survival of $80.4 \% .^{7}$ A study performed in Los Angeles analysed the data of 45 neonates and reported an overall survival of $72 \% .{ }^{13}$ A study performed in France analysed the data of 285 neonates and reported an overall survival of $84.2 \%{ }^{19}$ All three studies only reported on malignant solid tumours and haematological malignancies were not included.

A study performed in Natal analysed the data of 42 neonates diagnosed with malignant solid tumours and they reported a similar overall survival, compared with our study, of $42 \%{ }^{6}$

These findings suggested that neonates diagnosed with malignant solid tumours in South Africa, a middle-income country, have a worse prognosis compared to those diagnosed in high-income countries.
The overall treatment-related mortality in malignant tumours in this study was 3/16 (18.8\%), of which all patients died from treatment-related neutropaenic sepsis. This treatment-related mortality rate is significantly higher compared to high-income countries. The study performed in Poland reported an overall treatment-related mortality of $2.9 \%$ wherein $1 / 37$ patient died from surgery-related complications. ${ }^{7}$ The study performed in Los Angeles reported an overall treatment-related mortality of $2.2 \%$ wherein $1 / 45$ patient died, also from surgery-related complications. ${ }^{13}$ The study performed in France reported an overall treatment-related mortality of $5.3 \%$, wherein $15 / 285$ patients died from surgery-related complications. ${ }^{19}$

The study performed in Natal reported a significantly higher overall treatment-related mortality of $26.3 \%$, wherein $5 / 42$ patients died from treatment-related mortality. Three patients died from treatment-related causes not specified, one patient died from treatment toxicity and one from myelosuppresion. ${ }^{6}$

These findings reiterate that neonates diagnosed with malignant solid tumours in South Africa, a middle-income country, have a worse prognosis compared to those in highincome countries.

There are very little data available on neonatal tumours in low- and middle-income countries. Although this study reviewed a small number of patients, it clearly suggested that there is most likely a difference in the distribution of neonatal tumours diagnosed in middle-income countries compared to high-income countries. Despite this study being performed at a single centre, Chris Hani Baragwanath Academic Hospital is regarded as one of the largest hospitals in the world and the Paediatric Oncology unit at Chris Hani Baragwanath Academic Hospital is one of only three Paediatric Oncology units in Gauteng. Therefore, it can be assumed that this study covered a larger patient population than initially presumed.

There are many limitations in our study. Firstly, the rarity of neonatal tumours limited the analyses by diagnostic groups. Secondly, the inconsistency in the referral of haemangiomas impeded the inclusion of these tumours. Thirdly, incomplete records of patients prevented some patients from being included. Fourthly, incorrect diagnoses of tumour masses because of limited laboratory tests in the past might have influenced the study population. It was acknowledged that this study extended over a 25-year period, during which time methods of diagnosis, staging and tumour assessment have improved considerably.

It appears highly likely that a large number of neonatal tumours remain undiagnosed and that the incidence of neonatal tumours is probably much higher than that reported in this study. In view of the great potential for cure, we recommend that larger studies of these tumours, their pathologies, treatments and outcomes be performed with data collected from the National Tumour Registry. This may provide insight of the distribution of neonatal tumours present in South Africa, allow for more accurate incidences 
and possible aetiological agents, which may eventually lead to an improvement in the outcome of these patients.

\section{Conclusion}

Even though tumour masses do occur in the neonatal period, malignant neonatal tumours are very rare. It has been demonstrated that a large percentage of neonates diagnosed with malignant tumours in high-income countries can be successfully treated and cured. Clinicians involved in the care of neonates need to be better acquainted with diseasespecific signs of neonatal tumours to allow for early detection and referral to a Paediatric Oncology unit.

\section{Acknowledgements}

I would like to acknowledge all the staff at Chris Hani Baragwanath Academic Hospital Oncology unit, who provided me with all the necessary data: Dr Gita Naidu, Dr Bianca Rowe, Dr Linda Wainwright and Dr Stelios Poyiadjis.

\section{Competing interests}

The authors declare that they have no financial or personal relationships that may have inappropriately influenced them in writing this article.

\section{Authors' contributions}

T.M.S. was the project leader and D.M. was the supervisor and made conceptual contributions.

\section{References}

1. Allee WC, Ascher, KW, Beck CS, et al. Dorland's illustrated medical dictionary. 23rd ed. W.B. Saunders Company; 1957. p. 1482.

2. Moore SW, Satgé D, Sasco AJ. The epidemiology of neonatal tumours. Padiar Surg Int [serial online]. 2003 [cited 2012 Dec 11];19:509-519. Available from: http:// link.springer.com/article/10.1007/s00383-003-1048-8\#page-1

3. Davis CF, Carachi R, Young DG. Neonatal tumours: Glasgow 1955-86. Arch Dis Child [serial online]. 1988 [cited 2012 Dec 11];63:1075-1078. Available from: http://adc.bmj.com/content/62/1/19.full.pdf
4. Edward CH. Neonatal neoplasms. Int J Radiat Oncol Biol Phys [serial online]. 2000 [cited 2017 Feb 22];47(1):171-178. Available from: http://www.redjournal.org/ article/S0360-3016(00)00424-7/pdf

5. Crom DB, Wilimas JA, Green AA, et al. Malignancy in the Neonate. Med Pediatr Oncol [serial online]. 1989 [cited 2017 Feb 24];17:101-104. Available from: http://onlinelibrary.wiley.com/doi/10.1002/mpo.2950170206/pdf

6. Hadley GP, Govender D, Landers G. Malignant solid tumours in neonates: An African perspective. Pediatr Surg Int [serial online]. 2002 [cited 2012 Dec 10];18:653-657. Available from: http://link.springer.com/article/10.1007/s00383-002-0848-6

7. Raciborska A, Bilska K, Weclawek-Tompol J, et al. Solid cancers in the premature and the newborn: Report of three national referral centers. Pediatr Neonato [serial online]. 2016 [cited 2017 Feb 24];57:295-301. Available from: http://www. sciencedirect.com/science/article/pii/S1875957215001734

8. Campbell AN, Chan HSL, O'Brien A, et al. Malignant tumours in the neonate. Arch Dis Child [serial online]. 1987 [cited 2012 Dec 9];62:19-23. Available from: http:// adc.bmj.com/content/62/1/19.full.pdf

9. Lakhoo K, Sowerbutts H. Neonatal tumours. Pediatr Surg Int [serial online]. 2010 [cited 2012 Dec 6];26:1159-1168. Available from: http://www.springerlink.com/ index/7W62862R46217X73.pdf

10. Stevens MC. Neonatal tumours. Arch Dis Child [serial online]. 1988 [cited 2012 Dec 6];63:1122-1125. Available from: http://adc.bmj.com/content/63/10_Spec No/1122.full.pd

11. Deepak V. Tumors of the neonate. Univ Res J Den [serial online]. 2014 [cited 2016 Dec 21];4(1):16-21. Available from: https://www.researchgate.net/publication/ 272895829_Tumors_of_the_Neonate

12. Moore SW, Kaschula ROC, Albertyn R, et al. The outcome of solid tumours occurring in the neonatal period. Pediatr Surg Int [serial online]. 1995 [cited 2012 Dec 11];10:366-370. Available from: http://link.springer.com/article/10.1007/ s00383-003-1048-8\#page-1

13. Xue H, Horwitz JR, Smith MB, et al. Malignant solid tumors in neonates: A 40-year review. J Pediatr Surg [serial online]. 1995 [cited 2017 Jan 27];30(4):543-545. Available from: http://www.sciencedirect.com/science/article/pii/0022346895 901264?via\%3Dihu

14. Parkes SE, Muir KR, Southern L, et al. Neonatal tumours: A thirty-year populationbased study. Med Pediatr Oncol [serial online] 1994 [cited 2016 Dec 29]·22:309-317. Available from: http://onlinelibrary.wiley.com/doi/10.1002/mpo.2950220503/pdf

15. Orbach D, Sarnacki S, Brisse HJ, et al. Neonatal cancer. Lancet Oncol [serial online] 2013 [cited 2017 Jan 19]:14:609-620. Available from: http://www.sciencedirect. com/science/article/pii/S1470204513702365

16. Stefan DC, Siemonsma F. Delay and causes of delay in the diagnosis of childhood cancer. Pediatr Blood Cancer [serial online]. 2011 [cited 2017 Feb 9];56:80-85. Available from: https://www.ncbi.nlm.nih.gov/pubmed/21108442

17. Haimi MM, Peretz Nahum M, Weyl Ben Arush M. Delay in diagnosis of children with cancer: A retrospective study of 315 children. Pediatr Hematol Oncol [serial online]. 2004 [cited 2015 Oct 18];21:37-48. https://doi.org/10/1080/08880010490263579

18. Mfenyana S. The Chris Hani Baragwanath Hospital [homepage on the Internet]. Johannesburg [cited 2017 July 13]. Available from: https://www. chrishanibaragwanathhospital.co.za

19. Desandes E, Guissou S, Ducassou S, et al. Neonatal solid tumours: Incidence and survival in France. Pediatr Blood Cancer [serial online]. 2016 [cited 2017 July 15];63:1375-1380. Available from: http://onlinelibrary.wiley.com/doi/10.1002/ pbc.26006/abstract

20. Stefan $D C$, Stones DK, Wainwright RD, et al. Childhood cancer incidence in South Africa, 1987-2007. S Afr Med J [serial online]. 2015 [cited 2017 July 20];105(11):939-947. Available from: http://www.samj.org.za/index.php/samj/ article/view/9780 